See discussions, stats, and author profiles for this publication at: https://www.researchgate.net/publication/281360726

\title{
Aging Behavior of Commercial and Synthesized Dental Y-TZP Ceramics
}

Article in Materials Science Forum · June 2015

DOI: 10.4028/www.scientific.net/MSF.820.297

CITATION

1

8 authors, including:

$$
\text { A. Arata }
$$

Instituto de Pesquisas Energéticas e Nucleares

17 PUBLICATIONS 51 CITATIONS

SEE PROFILE

Walter Yoshito

Instituto de Pesquisas Energéticas e Nucleares

35 PUBLICATIONS 57 CITATIONS

SEE PROFILE
READS

118

João Paulo Machado

National Institute for Space Research, Brazil

52 PUBLICATIONS 422 CITATIONS

SEE PROFILE

Valter Ussui

Instituto de Pesquisas Energéticas e Nucleares

68 PUBLICATIONS 213 CITATIONS

SEE PROFILE

Some of the authors of this publication are also working on these related projects:

coatings View project

Project Development of $\mathrm{Cr} 3 \mathrm{C} 2-25(\mathrm{Ni20Cr})$ nanostructured coatings. View project 


\title{
Quantitative phase analysis from X-ray diffraction in Y-TZP dental ceramics: A critical evaluation
}

\author{
A. Arata ${ }^{a, d, *}$, T.M.B. Campos $^{b}$, J.P.B. Machado ${ }^{c}$, D.R.R. Lazar ${ }^{d}$, V. Ussui ${ }^{d}$, \\ N.B. Lima ${ }^{d}$, R.N. Tango ${ }^{a}$ \\ a Institute of Science and Technology, Universidade Estadual Paulista Julio de Mesquita Filho, São José dos Campos, \\ São Paulo, Brazil \\ ${ }^{\mathrm{b}}$ Instituto Tecnológico de Aeronáutica (ITA), São José dos Campos, São Paulo, Brazil \\ ${ }^{c}$ Associated Laboratory of Sensors and Materials, National Institute for Space Research (INPE), São José dos Campos, \\ São Paulo, Brazil \\ ${ }^{\mathrm{d}}$ Materials Science and Technology Center (CCTM), Nuclear and Energy Research Institute - National Nuclear Energy \\ Commission (IPEN - CNEN/SP), São Paulo, Brazil
}

\section{A R T I C L E I N F O}

Article history:

Received 4 April 2014

Received in revised form

13 August 2014

Accepted 15 August 2014

Available online $\mathrm{xxx}$

Keywords:

Artificial ageing

Y-TZP

Characterisation

Rietveld method

\begin{abstract}
A B S T R A C T
The dentistry literature shows consensus to use the Garvie and Nicholson equation modified by Toraya to quantify the Y-TZP phase transformation. However, this method does not include the possibility of cubic phase transformation and crystallographic texture after artificial ageing, and in this case, it is possible to observe errors of quantification.

Objectives: The aim of this study was to evaluate a dental Y-TZP ageing kinetic of phase transformation under pressure and hydrothermal conditions $\left(130^{\circ} \mathrm{C}, 2 \mathrm{bar}\right)$ and to compare the methods of quantification by the equation of Garvie and Nicholson modified by Toraya and the Rietveld refinement method.

Methods: Discs of Y-TZP (12 mm $\varnothing \times 1.2 \mathrm{~mm}$ in height) were divided into groups $(n=4)$ according to the ageing times (in the range of 6 and $138 \mathrm{~h}$ ). The superficial characterisation was made using SEM and the XDR for crystallographic analysis.

Results: An aggressive superficial degradation process at the beginning of phase transformation in $6-10 \mathrm{~h}$ of ageing was observed by SEM. The phase transformation quantification showed differences between the methods. It was observed the increase and stabilisation of monoclinic phase until $80 \%$ at 40 h of ageing by the Garvie and Nicholson modified by Toraya equation, compared to $60 \%$ of monoclinic phase and approximately $30 \%$ of cubic phase observed by the Rietveld method.

Conclusion: The Toraya equation showed an overestimated result of monoclinic quantification compared to the Rietveld method.

Clinical significance: The overestimated result of monoclinic phase could lead to different interpretation about the dental Y-TZP ageing process.
\end{abstract}

(C) 2014 Elsevier Ltd. All rights reserved.

\footnotetext{
* Corresponding author at: Materials Science and Technology Center (CCTM), Nuclear and Energy Research Institute - National Nuclear Energy Commission (IPEN - CNEN/SP), Av. Prof. Lineu Prestes 2242, Cidade Universitária, São Paulo/SP 05508-000, Brazil.

Tel.: +55 113122 9225; fax: +55 1131339276 .

E-mail address: anelyse@uol.com.br (A. Arata).

http://dx.doi.org/10.1016/j.jdent.2014.08.010

0300-5712/(C) 2014 Elsevier Ltd. All rights reserved.
} 


\section{Introduction}

The increased interest for dental aesthetic materials has led to several studies using yttria-stabilised tetragonal zirconia polycrystal (Y-TZP) in regard to its high fracture toughness, high mechanical resistance, biocompatibility and low rate of wear. . $2,3,4^{-}$

Zirconia has a polymorphic crystal structure that can be found in three principal allotropes: monoclinic (m), cubic (c), and tetragonal $(\mathrm{t})$. The monoclinic phase is stable at room temperature until $1170{ }^{\circ} \mathrm{C}$, after this temperature, until $2370^{\circ} \mathrm{C}$, it is found at the tetragonal form and after that it is observed the cubic phase that is stable until its fusion. For tetragonal phase stability at room temperature, $3 \% \mathrm{~mol}$ of yttrium oxide it is added to zirconia. ${ }^{5,6}$ When a crack starts in this material, grains of tetragonal zirconia transform into monoclinic grains that have higher volume, in this case it is observed a resistance that hampers the crack propagation. ${ }^{4,7-9}$

Some problems related to premature Y-TZP degradation, called as low-temperature degradation, was described in 1981 by Kobayashi et al. ${ }^{10}$, in femoral heads implants maintained in temperatures between $100{ }^{\circ} \mathrm{C}$ and $500{ }^{\circ} \mathrm{C},{ }^{11,12}$ in contact with water $^{13}$ or corporeal fluids. This process is time dependent and can lead to a superficial roughness where grains are detached from the structure that can be associated with micro-cracks, ${ }^{14}$ generating a decrease of mechanical properties. ${ }^{15}$ Furthermore, when ceramics are submitted to mechanical load lower than the critical level in humid atmosphere, as the oral environment, it was observed that pre existent defects can present a slow and stable growing. This phenomenon is known as slow crack growth that can lead to a long-term degradation. ${ }^{16}$ The microcracking caused by the degradation may induce the slow crack growth that can lead to a catastrophic failure of the material. ${ }^{17}$

The commercial dental Y-TZP has been the material selected for aesthetic metal free restorations. However, there is difficulty in finding standardisation for the ageing methods studies in the dentistry field. Although there is plenty of information about Y-TZP femoral heads ageing, ${ }^{18,19,20}$ and some in vitro low-temperature degradation in dental Y-TZP studies, ${ }^{21,22}$ only a few in vivo studies were performed regarding the long-term survival of dental $\mathrm{Y}-\mathrm{TZP}^{23,24}$ it is still necessary to understand the in vivo ageing behaviour of a dental Y-TZP.

The condition of load, sintering, composition and processing can be different between the femoral joints and dental YTZP that can lead to different ageing behaviours. Furthermore, all methods observed to quantify the amount of monoclinic phase after ageing are based in two basic equations developed by Garvie and Nicholson ${ }^{25}$ and Toraya et al. ${ }^{26}$ using the X-ray diffraction analysis.

Garvie and Nicholson ${ }^{25}$ calculated the amount of monoclinic phase in powders using cubic (111) and monoclinic (111), (-111) peaks. For this same purpose, Toraya et al. ${ }^{26}$ used intensities of tetragonal (1 01 ) and monoclinic (-1 11 ), (111) reflections in mixed powders. The particles had spherical shape and did not present significant preferred orientation. An X-ray powder pattern fitting (refinement method) was used to quantify the amount of monoclinic phase. However, both the methods of quantification were developed for powder materials that do not present preferred orientation. Moreover, no calculation was made assuming that the material could present the tetragonal, cubic and monoclinic phase. ${ }^{26}$

Chevalier et al. ${ }^{27}$ described that, in ceramics, the tetragonal phase transformation happens preferentially at the plane (1 0 1)t and suggested that the preferential orientation occurs after degradation due to the fact that the sample surface at the beginning of the process presented a random distribution of unit cells of tetragonal phase. However, when these cells suffer a degradation process, the planes $\left(\begin{array}{lll}1 & 0 & 1\end{array}\right) \mathrm{t}$, parallel to surface, transforms on the plane $(-111) \mathrm{m}$, showing the preferential orientation phase transformation with a higher intensity compared to the peak $\left(\begin{array}{llll}1 & 1 & 1\end{array}\right) \mathrm{m}$. Hence the $\left(\begin{array}{lll}1 & 0 & 1\end{array}\right) \mathrm{t}$ peak decreases compared to the other tetragonal peaks. Moreover, it was observed that studies of Y-TZP ageing, based on the quantification of monoclinic phase through the Garvie and Nicholson modified by Toraya equation (Toraya equation) could lead to an overestimation of results.

The international organisation for standardisation (ISO) 13,356 for Y-TZP implants ageing is based on the studies of YTZP femoral heads ageing performed by Chevalier et al. ${ }^{28}$ Chevalier et al. ${ }^{27}$ and Deville et al. ${ }^{29}$ using the water steam at $134{ }^{\circ} \mathrm{C}, 2$ bar. Chevalier et al. ${ }^{28}$ affirm that the Y-TZP ageing behaviour depends on the ceramic microstructure. Grain size and the bulk density are factors that could lead to different ageing results compared to ceramics having the same chemical composition. Furthermore, the ceramic processing method, such as cooling, machining, polishing, grinding and the annealing can also lead to different ageing behaviour associated with the residual stress.

In order to aggregate information necessary to the knowledge of dental Y-TZP ageing behaviour, the aim of this study was to evaluate the phase transformation of commercial dental Y-TZP after ageing using different analysis methods. Specifically, to determine the kinetic of phase transformation after artificial ageing and to compare the methods of quantification by the equation of Garvie and Nicholson modified by Toraya ${ }^{26}$ and the Rietveld refinement method. ${ }^{30}$ To obtain information in regard to the type of nucleation and grain formit was used in this study the kinetic model developed by Melvin Avrami.

\section{Materials and methods}

Blocks of pre-sintered commercial dental Y-TZP (VITA InCeram 2000 YZ CUBES 4019; VITA Zanhfabrik, Germany) were machined and sectioned to roundedsamples $(15 \mathrm{~mm}$ $\varnothing \times 2 \mathrm{~mm}$ height). The samples were ground and polished using sandpaper of 400, 600, 1200, 2400 and 3000 grits (Norton Saint-Gobain, Brazil) and ultrasonically cleaned (Vitasonic VITA Zanhfabrik, Germany) in isopropyl alcohol for $15 \mathrm{~min}$ to remove any $\mathrm{SiC}$ residues, followed by sintering at $1530^{\circ} \mathrm{C}$ during $120 \mathrm{~min}$ (Zyrcomat T; Vita Zahnfabrick, Germany). After sintering process, for chemical composition analysis, the samples were analyzed by energy dispersive X-ray spectroscopy - EDS (EDX-720, Shimadzu, USA). 
To follow the kinetics of phase transformation of dental Y-TZP, a hydrothermal pressurised reactor was used (4566 Minireactor, Parr Instrument, USA). The samples were introduced in a recipient filled with ionised water and heated for $138 \mathrm{~h}$ at $130^{\circ} \mathrm{C}, 2.07$ bar. To determine the amount of formed monoclinic phase as a function of the ageing time at constant temperature, four samples per time of ageing were taken away progressively in accord with the time of heating (Gc: no treatment, G6: 8; 10; 12; 14; 20; 30; 40; 48; 60; 84; 108 and $138 \mathrm{~h}$ ).

The samples named Gc, G6, G8, G10, G12, G14, G20, G30, G40 were analyzed by SEM (Philips XL30, Philips, Netherlands), high vacuum, $1 \mathrm{kV}$, WD $11.7 \mathrm{~mm}$, in order to observe the surface.

All the samples were submitted to X-ray diffraction analysis (XDR) (X'pert Powder, PANalytical, Netherlands), $\mathrm{Cu}-\mathrm{K} \alpha(\lambda=0.154 \mathrm{~nm}), 45 \mathrm{kV}, 40 \mathrm{~mA}$. Scans were performed from $20^{\circ}$ to $80^{\circ}$, step size of $0.02^{\circ}, 10 \mathrm{~s}$ per step.

The monoclinic phase was quantified by the Toraya equation (Eqs. (1) and (2)) using the peaks at $28^{\circ}, 30^{\circ}$ and $31.2^{\circ}$ by two different methodologies: the first was obtained using the intensity of the peak top (group 1) and the second using the peak area (group 2). Both intensities were obtained after the baseline subtraction.

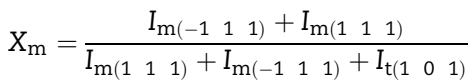

where, $X_{\mathrm{m}}$, monoclinic fraction; $I_{\mathrm{m}\left(-11_{1}\right)} \approx 31.2^{\circ}$, monoclinic peak intesity $\left(\mathrm{ZrO}_{2}\right) ; I_{\mathrm{m}}\left(\begin{array}{ll}1 & 1\end{array}\right) \approx 30^{\circ}$, monoclinic peak intesity $\left(\mathrm{ZrO}_{2}\right), \mathrm{I}_{\mathrm{t}\left(\begin{array}{l}1 \\ 0\end{array}\right)} \approx 28^{\circ}$, tetragonal peak intesity $\left(\mathrm{ZrO}_{2}\right), \mathrm{F}_{\mathrm{m}}$, volumetric fraction of monoclinic phase.

$F_{m}=\frac{1.311 X_{m}}{1+0.311 X_{m}}$

All aged groups were analysed through the Rietveld refinement method aiming the comparison of results of monoclinic phase quantification between the traditional Toraya equation and the Rietveld method using the programme General Structure Analysis System (GSAS). The crystal structure data (atom coordinates, thermal parameters and unit cell parameters) were obtained from the Inorganic Crystal Structure Data Base - ICSD. The computation adjustments performed were the scale factors, unit cell parameter, pattern background polynomial parameter, $2 \theta$-scale offset and peak profile functions (pseudo-Voigt with asymmetry). Refinement trials of two types were conducted, the first with random orientation and the second with the spherical harmonic preferential orientation (ODF).

To calculate the relationship between the ageing time and amount of monoclinic phase it was used the Mehl-AvramiJohnson equation modified by Kolgomorow (Johnson-MehlAvrami-Kolmogorow - JMAK) for values lower than $100 \%$ of monoclinic saturation (Eq. (3)):

$\mathrm{V}_{\mathrm{m}}=\mathrm{V}_{\mathrm{m} 0}+\left(\mathrm{V}_{\mathrm{mf}}-\mathrm{V}_{\mathrm{m} 0}\right)\left(1-\exp (-b t)^{n}\right)$

where, $V_{\mathrm{mo}}$, level of initial monoclinic phase; $V_{\mathrm{mf}}$, level of monoclinic phase saturation; $b$, parameter dependent of the rate of nucleation and monoclinic growth speed parameter; $n$, Avrami exponent-type of spatial grain growth.

\section{Results}

The EDX analysis showed the presence of $92.92 \%$ of zirconium oxide, $5.38 \%$ of ytrrium oxide and $1.6 \%$ of hafnium oxide (Table 1).

SEM analysis of Y-TZP sintered sample (Gc) shows regularity of the grains and visible contour (Fig. 1a). After ageing treatment, SEM images showed an initial aggressive process at the G6-G10 groups. It was observed the majority of superficial grains suffering a disrupting process like a pulverisation process with boundary grain distinctness lost (Fig. 1b-d). With increasing of the ageing time, it was possible to observe the improvement of the grains boundaries limits. However, areas of pull out grains were observed (Fig. 1e-i).

According to the Toraya equation, it was observed the progression of increase of the monoclinic peaks at $28^{\circ}$ and $31.2^{\circ}$ relatively to tetragonal peak at $30^{\circ}$. The comparison with Table 2 shows an accentuated increase at the peak $\left(\begin{array}{lll}1 & 1 & 1\end{array}\right) \mathrm{m}$ in relation to the peak $(-111)$ with the increase of ageing time. Besides, the relative peaks intensities also change for tetragonal phase when compared to the isotropic diffraction pattern presented in Table 2. After $30 \mathrm{~h}$ the $\left(\begin{array}{lll}1 & 1 & 1\end{array}\right) \mathrm{m}$ and $\left(\begin{array}{ll}1 & 0\end{array}\right) \mathrm{t}$ peaks intensities are equivalent and after $40 \mathrm{~h}$ it is observed an inversion of theses peaks (Fig. 2). The Fig. 3 shows the XRD pattern with the deconvolution of the tetragonal, monoclinic and cubic phase.

Through the Toraya equation the percentage of monoclinic phase was determined using the two groups of data as described above. This data was inserted at the Avrami equation. The maximum rate of phase transformation was around $80 \%$ for group 1 and $75 \%$ for group 2 . The " $n$ " values were 0.97 and 0.66 for groups 1 and 2, respectively, are related to the type of growth. These results suggested that the growth occurred in one dimension. The constant speed was 0.0456 for group 1 and 0.0764 for group 2 (Fig. $4 \mathrm{a}$ and b respectively).

With the increase of ageing time, it was observed an enlargement at the tetragonal peak (1 01 1)t that suggested the peak of tetragonal phase was overlapping the cubic phase peak at the left side. The Toraya equation does not take this fact in to account. The Rietveld method was conducted considering the presence of three phases: monoclinic, tetragonal and cubic and the phase percentage profile obtained is presented in the Fig. 5. It was observed an accentuated increase of monoclinic phase until $40 \mathrm{~h}$ and its stabilisation in approximately $60 \%$ of transformed phase.

Using the Rietveld method it was also possible to calculate the percentage of monoclinic phase and to employ the linear Avrami equation. The results showed a saturation around $60 \%$ of monoclinic phase and one dimension type of process growth $(n=0.63)$. The speed constant was 0.077 (Fig. 4c).

Table 1 - YZ chemical composition, corresponding to the zirconia stabilisation with $3 \% \mathrm{~mol}$ of yttria.

\begin{tabular}{lcl} 
Oxides & Percentage (wt\%) & s.d. \\
\hline $\mathrm{ZrO}_{2}$ & 92.922 & 0.080 \\
$\mathrm{Y}_{2} \mathrm{O}_{3}$ & 5.381 & 0.017 \\
$\mathrm{HfO}_{2}$ & 1.607 & 0.017 \\
\hline
\end{tabular}



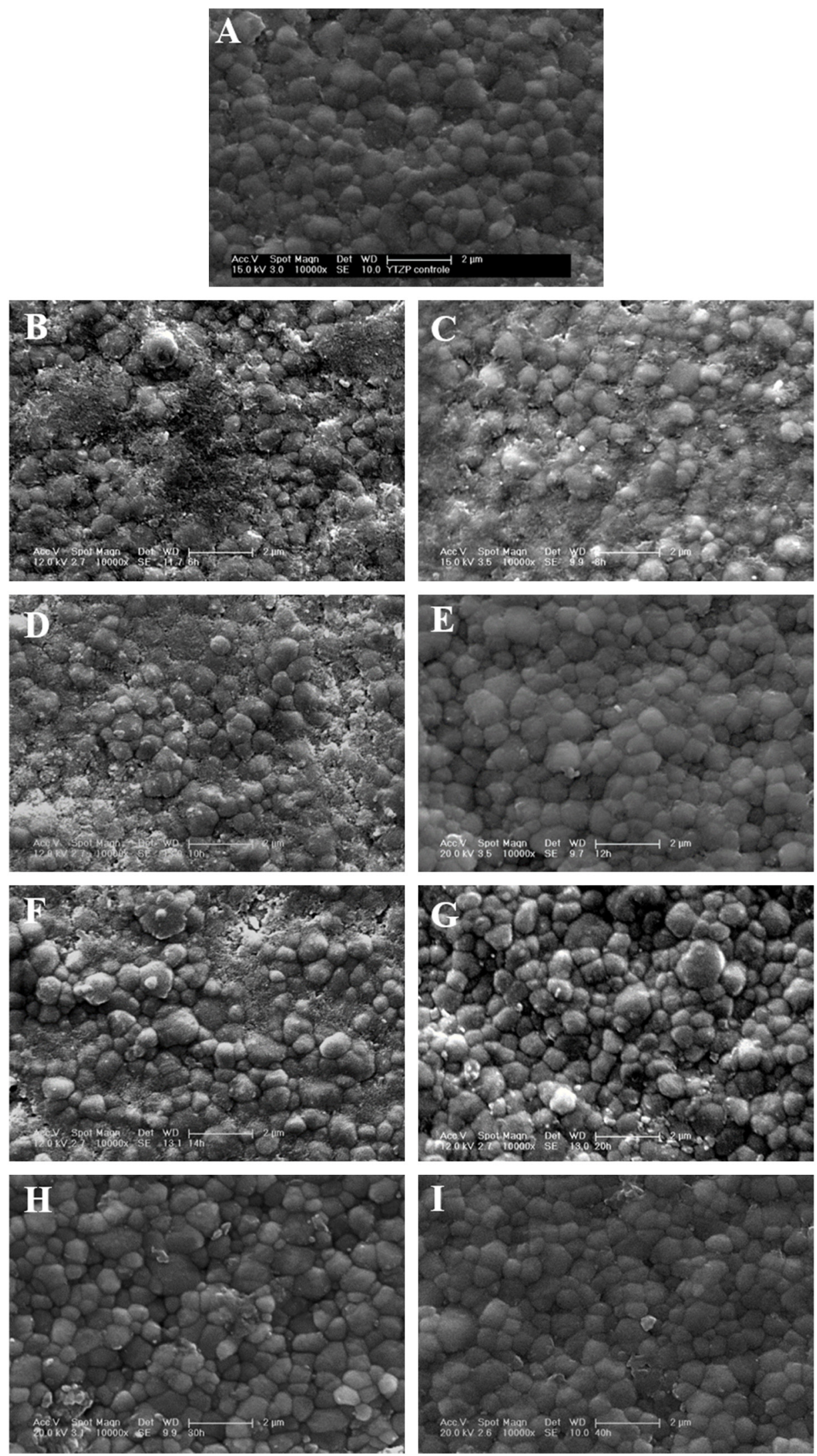

Fig. 1 - SEM micrographs of Y-TZP samples of the control group and after ageing: (A) control group; (B) G6 hours; (C) G8 hours; (D) G10 hours; (E) G12 hours; (F) G14 hours; (G) G20 hours; (H) G30 hours; (I) G40 hours. 
Table 2 - Relation of peaks and relative intensity extracted from the isotropic X-ray diffraction pattern.

\begin{tabular}{lcccccc} 
& \multicolumn{2}{l}{ Peaks } & & $2 \theta$ (degrees) & Relative intensity (\%) \\
\cline { 2 - 4 } & $h$ & $k$ & $l$ & & 99.9 \\
\hline Tetragonal & 1 & 0 & 1 & 0 & 34.86 & 13.1 \\
Tetragonal & 1 & 1 & 1 & 28 & 100 \\
Monoclinic & -1 & 1 & 1 & 31.2 & 68 \\
Monoclinic & 1 & 1 & & & \\
\hline
\end{tabular}

\section{Discussion}

The EDS analysis showed that the Vita YZ sample presented zirconium oxide, yttrium oxide and hafnium oxide (Table 1). By the X-ray fluorescence spectroscopy, Lorente et al. ${ }^{21}$ found

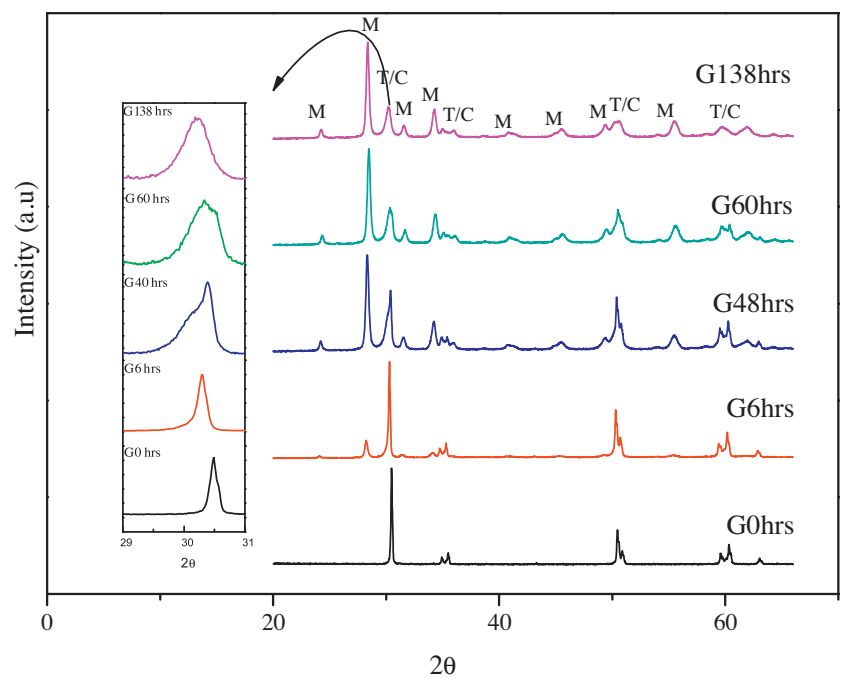

Fig. 2 - XRD diffraction patterns showing the monoclinic phase progression from 6 to 138 ageing hours $\left(130^{\circ} \mathrm{C}\right)$ compared to the control group.

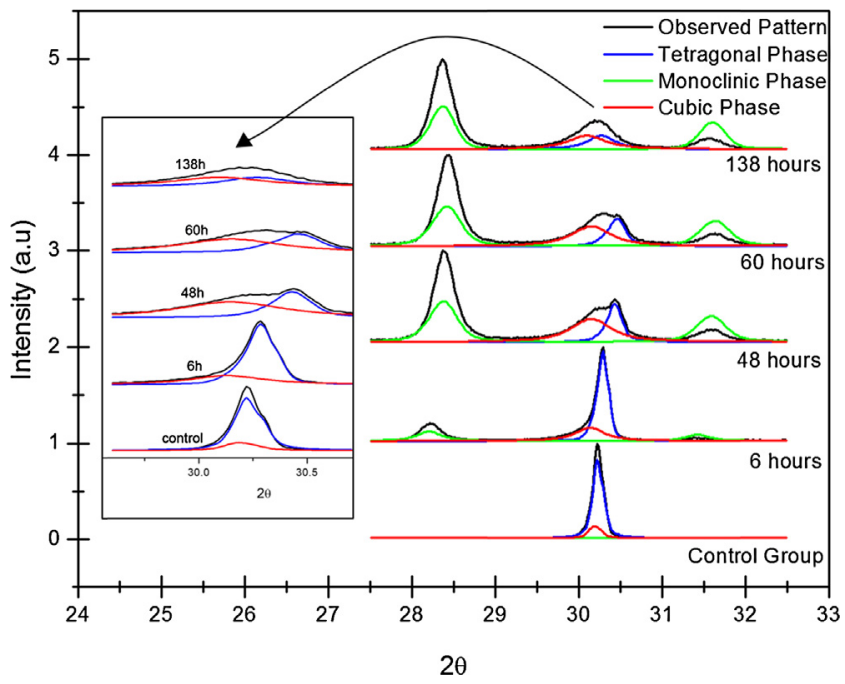

Fig. 3 - XRD diffraction patterns with the deconvolution of the tetragonal, monoclinic and cubic phase of the control and aged groups. the presence of the same elements at the Lava System and the addition of alumina $(0.42 \%)$ and silica $(0.21 \%)$.

Deville et al. ${ }^{31}$ observed the influence of surface finish and residual stresses on the ageing sensitivity of biomedical grade zirconia and they observed that rough polishing produced a

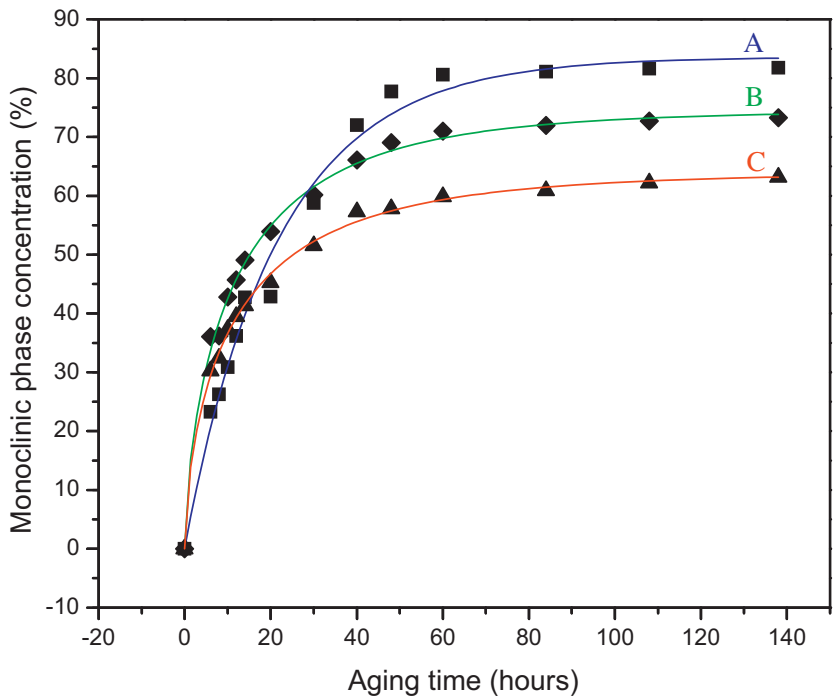

Fig. 4 - Avrami - monoclinic phase transformation calculated: (A) from the peaks height by Garvie and Nicholson equation modified by Toraya; (B) from the area under the peaks by Garvie and Nicholson equation modified by Toraya; (C) by Rietveld method.

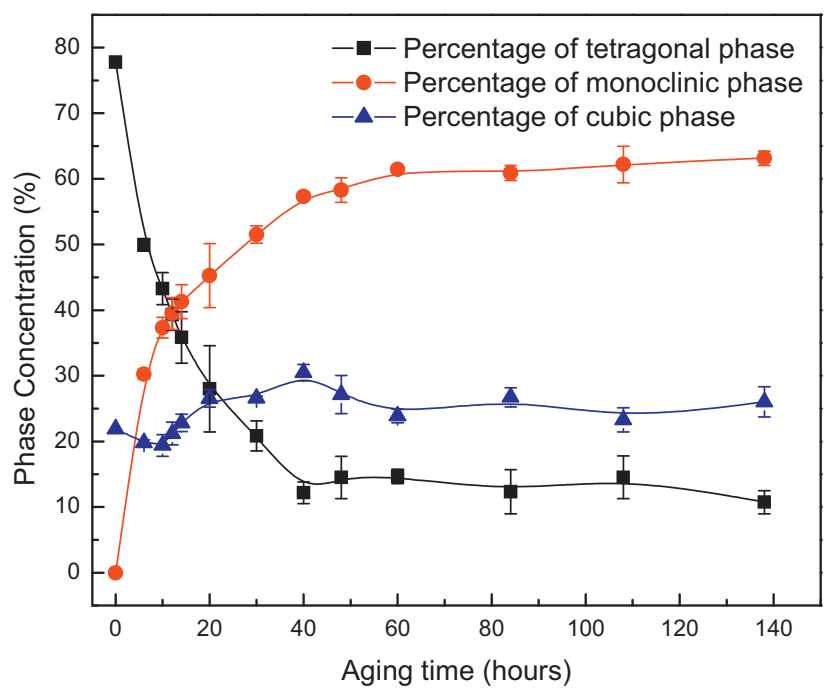

Fig. 5 - Fraction of tetragonal, cubic and monoclinic phase (Rietveld method) as a function of the ageing time. 
compressive surface stress layer that was beneficial for the ageing resistance. In contrast, the smooth polishing procedure produced preferential transformation nucleation around the scratches. Based in this conclusions, the procedure adopted in this paper did not included the polishing process with diamond pastes after sintering to not add one more variable at the ageing study.

Chevalier et al. ${ }^{28}$ and Deville et al. $^{29}$ pointed out the biomedical femur heads premature degradation problem when sterilised in water steam, which is a requirement for a surgical procedure. In dentistry, the dental prosthesis is not sterilised before the clinical procedure. To accelerate the YTZP ageing process in this study it was opted the use a hydrothermal pressurised reactor that allowed submerging the samples in ionised water during all ageing test that was maintained at $130^{\circ} \mathrm{C}( \pm 2), 2.07$ bar during $12 \mathrm{~h}$.

The SEM results showed an initial aggressive process at the G6-G10 groups, grains pull out and difficulty to observe the boundary grain limit (Fig. 1b-d). The possible reason for this abrupt process may be given by the fact that the surface before ageing was stable and the grains were very well organised spatially (Fig. 1a). With the volumetric grain growth, related to the $\mathrm{t}-\mathrm{m}$ phase transformation, there was no free space for the grains to grow and reorganise, so compressive forces started around the grains that culminated in grain breaking process. This process, in this work, was called as a surface pulverisation. This fact was observed by SEM (Fig. 1b-d). Furthermore, with the increase of ageing time, an improvement was observed at the distinctness of grains boundary limits (Fig. 1e-i). Probably the presence of surface pores permitted the grain growth and self-accommodation. Associated with this fact, the increase of the water temperature could lead to a heat treatment of the surface that causes a better visibility of the grain boundary with the increase of ageing time. Through the obtained diffractograms, it was verified that the relative intensities of the peaks diffraction did not follow the isotropic X-ray diffraction pattern for both phases. This indicates preferential crystallographic transformation of tetragonal to monoclinic phase (Fig. 2 and Table 2). This phenomenon can be attributed to martensitic phase transformation process which occurs with a shear of the superficial plane with the subjacent plane generating a new phase. Moreover, Chevalier et al. ${ }^{27}$ described that the tetragonal phase transformation happens preferentially at the plane $\left(\begin{array}{lll}1 & 0 & 1\end{array}\right)$ t. In this way, this work suggests that the preferential orientation is given to the fact that the sample surface presented aleatory disposed unit cells of tetragonal phase. However, when these cells suffer a one dimension degradation process, the planes (1 01 )t parallel to surface transforms on the plane $(-111) \mathrm{m}$, showing the preferential orientation phase transformation with a higher intensity compared to the peak (1 111$) \mathrm{m}$. Hence the $\left(\begin{array}{lll}1 & 0 & 1\end{array}\right) \mathrm{t}$ peak decreases, compared to the other tetragonal peaks.

Using the Eqs. (1) and (2), it was possible to observe that the monoclinic transformation for sample aged for $40 \mathrm{~h}$ was $80 \%$ or $75 \%$ depending on the methodology of data collection. However, preferential orientation associated to the fact that only 3 peaks are used to calculate the amount of monoclinic phase, leads an error of phase quantification that overestimated the amount of monoclinic transformed phase.
To compare the data obtained through the Toraya equation, the quantification of phases were made through the Rietveld method. It was observed an enlargement of the (101)t peak that increased with the ageing time, that suggested a tetragonal and cubic peaks overlap. The Garvie and Nicholson equation does not consider any cubic phase. Through the Rietveld method it is possible to calculate the amount of phase using the whole diffraction pattern that gives more precise data. ${ }^{30}$ The overlapping peaks problem was minimised permitting the maximum extraction of the patterns data (Fig. 3). Through the refined patterns, $60 \%$ of monoclinic phase was observed in 40 ageing hours (Fig. 5). The results contrast with $80 \%$ or $75 \%$ of monoclinic phase observed by the Toraya equation, with a difference of $20 \%$ or $15 \%$ (Fig. $4 \mathrm{a}$ and $b$ ). Lorente et al. ${ }^{21}$ used the Rietveld method to quantify the monoclinic phase transformation at the higher ageing time $(168 \mathrm{~h})$ and observed the presence of cubic phase. Chevalier et al. ${ }^{27}$ concluded that none of his group experiments led to $100 \%$ of monoclinic phase after ageing, even in prolonged times. After observing the peaks overlap, it was possible to quantify the amount of cubic and tetragonal phase through the Rietveld method, the increase of the cell parameter of the cubic phase with the increase of the amount of monoclinic phase and decrease of tetragonal phase was observed (Fig. 4c). The enlargement of the cubic peak after ageing was attributed to the higher amount of yttrium at the cubic phase. The higher amount of yttrium at the cubic lattice increased the cell parameter of the cubic phase promoting a visible enlargement at the (1 11 1) cubic peak as shown in Fig. 3. According with Matsui et al. ${ }^{32}$ during the Y-TZP sintering from $1100{ }^{\circ} \mathrm{C}$ to $1700{ }^{\circ} \mathrm{C}$ it is possible to observe the segregation of yttrium content around the tetragonal grains. The higher amount of yttrium could explain the increase of the cubic cell parameter observed in this study.

It was difficult to compare the kinetic curve of phase transformation on this work with other studies. Primarily, by the preferential orientation that was presented at the YZ (Vita) after ageing, resulting in overestimated monoclinic phase results by the Toraya equation and for the fact that this equation does not include the presence of cubic phase that was shown through the diffraction pattern obtained in this work. Even with the Toraya equation, the results of monoclinic phase transformation stabilisation of a dental Y-TZP (around $80 \%$ ) were lower than the results found by Chevalier et al. ${ }^{28}$ at $130{ }^{\circ} \mathrm{C}$ in orthopaedics Y-TZP (around 90\%). A higher dental YTZP ageing resistance was also related by Lorente et $a .^{21}$ in samples produced by ageing at $140{ }^{\circ} \mathrm{C}$ in water steam at atmospheric pressure, and the author reported a monoclinic phase saturation of $68 \%$ calculated by Toraya equation and a saturation of $48 \%$ calculated by Rietveld methods.

The MAJ (Avrami) equation is used when the saturation of monoclinic phase is close to $100 \%$, as used by Chevalier et al. ${ }^{28}$ However, in this study it was observed the maximum of $80 \%$ of monoclinic phase by the Garvie and Nicholson equation modified by Toraya, and $60 \%$ of monoclinic phase saturation identified by the Rietveld method. Therefore, it was necessary to use the MAJ equation modified by Kolmogorow (JMAK). The results obtained by the Toraya equation and the Rietveld method presented the " $n$ " value lower than $1(n<1)$, suggesting that the process growth occurs in one dimension. 
These data are different than the results found by Chevalier et al. $^{28}$, which " $n$ " value was 3.6 for the orthopaedics Y-TZP, indicating the three dimension grain growth. However, the higher values of monoclinic saturation found by Chevalier et al. $^{28}$ in orthopaedic Y-TZP after ageing, compared to the nanometric structure obtained in this work, could be a consequence of the differences of structure, processing method and the grain size. But the main source of the differences among the results came from the phase quantification methodology. Using the same data, but different methodologies leads up to $20 \%$ of monoclinic saturation differences.

Due to the characteristic type of phase transformation occurred in the planes shear (martensitic transformation), inducing preferred orientation of crystalline planes, the Toraya equation could lead to an overestimated value of monoclinic phase saturation. Despite the difficulty of the Rietveld method, the graphs refinement and obtained phase quantification using more peak areas, this calculation is extremely indicated to a higher quantification precision.

\section{Conclusion}

Through the methodology used at this present study and the obtained results, it was possible to conclude that the ageing procedure using a hydrothermal pressurised reactor allowed the kinetic study of phase transformation and gave aging results for dental Y-TZP. The dental Y-TZP kinetic curve of transformation presented lower levels of monoclinic phase compared with the literature values for orthopaedics Y-TZP. The Rietveld method indicated lower amount of monoclinic phase compared to the Garvie and Nicholson equation modified by Toraya due to the fact of the preferential orientation observed and the insertion of cubic phase. Therefore, the Rietveld method is indicated. The aged groups presented a maximum saturation of monoclinic phase of $80 \%$ through the Garvie and Nicholson equation modified by Toraya, compared to $60 \%$ through the Rietveld method.

\section{Conflict of interest statement}

The authors declare there are no conflicts of interest.

\section{Acknowledgement}

This study was supported by a grant from the Fundação de Amparo à Pesquisa do Estado de São Paulo - FAPESP (Process 2010/13951-5).

\section{R E F E R E N C E S}

1. Rosenblum MA, Schulman A. A review of all-ceramic restorations. The Journal of American Dental Association 1997;128(3):297-307.

2. Qualtrough AJ, Piddock V. Dental ceramics: what's new? Dental Update 2002;29(1):25-33.

3. Aboushelib NM, de Jager N, Kleverlaan CJ, Feilzer AJ. Effect of loading method on the fracture mechanics of two layered all-ceramic restorative systems. Dental Materials 2007;23(8):952-9.

4. Manicone PF, Rossi Iommetti P, Raffaelli L. An overview of zirconia ceramics: basic properties and clinical applications. Journal of Dentistry 2007;35(11):819-26.

5. Garvie RC, Hannink RHJ, Pascoe RT. Ceramic steel? Nature 1975;258:703-4.

6. Piconi C, Maccauro G. Zirconia as a ceramic biomaterial. Biomaterials 1999;20(1):1-25.

7. Kim DJ, Lee MH, Lee DY, Han JS. Mechanical properties, phase stability, and biocompatibility of (Y, Nb)-TZP/Al $\mathrm{O}_{3}$ composite abutments for dental implant. Journal of Biomedical Materials Research 2000;53(4):438-43.

8. Larsson C, Holm L, Lövgren N, Kokubo Y, Vult von Steyern P. Fracture strength of four-unit Y-TZP FPD cores designed with varying connector diameter. An in-vitro study. Journal of Oral Rehabilitation 2007;34(9):702-9.

9. Adatia ND, Bayne SC, Cooper LF, Thompson JY. Fracture resistance of yttria-stabilized zirconia dental implant abutments. Journal of Prosthodontics 2009;18(1):17-22.

10. Kobayashi K, Kuwajima H, Masaki T. Phase change and mechanical properties of $\mathrm{ZrO}_{2}-\mathrm{Y}_{2} \mathrm{O}_{3}$ solid electrolyte after ageing. Solid State Ionics 1981;3-4:489-93.

11. Sato T, Shimada M. Crystalline phase change in yttriapartially stabilized zirconia by low-temperature annealing. Journal of the American Ceramic Society 1984;68(10):C212-3.

12. Sato T, Shimada M. Transformation of yttria-doped tetragonal $\mathrm{ZrO}_{2}$ polycrystals by annealing in water. Journal of the American Ceramic Society 1985;68(6):356-9.

13. Yoshimura M, Noma $T$, Kawabata $K$, Somiya S. Role of $\mathrm{H}_{2} \mathrm{O}$ on the degradation process of Y-TZP. Journal of Material Science Letters 1987;6(4):465-7.

14. Lilley E. Review of low temperature degradation of tetragonal zirconia ceramics. In: Tressler RE, McNallen $\mathrm{H}$, editors. Ceramics transactions, corrosion and corrosive degradation of ceramics. Westerville: American Ceramic Society; 1990.

15. Grant KL, Rawlings RD, Sweeney R. Effect of HIPping, stress and surface finish on the environmental degradation of $\mathrm{Y}$ TZP ceramics. Journal of Material Science 2001;12(6):557-64.

16. Myers ML, Ergle JW, Fairhurst CW, Ringle RD. Fatigue failure parameters of IPS-Empress porcelain. Journal of Dental Research 1994;7(6):549-53.

17. Chevalier J, Gremillard L, Virkar AV, Clarke DR. The tetragonal-monoclinic transformation in zirconia: lessons learned and future trends. Journal of the American Ceramic Society 2009;92(9):1901-20.

18. Haraguchi K, Sugano N, Nishii T, Miki H, Oka K, Yoshikawa $\mathrm{H}$. Phase transformation of a zirconia ceramic head after total hip arthroplasty. Journal of Bone Joint Surgery 2001;83(7):996-1000.

19. Santos EM, Vohra S, CatledgeSA. McClenny MD, Lemons J, Moore KD. Examination of surface and material properties of explanted zirconia femoral heads. The Journal of Arthroplasty 2004;19(7):30-4.

20. Masonis JL, Bourne RB, Ries MD, McCalden RW, Salehi A, Kelman DC. Zirconia femoral head fractures. The Journal of Arthroplasty 2004;19(7):898-905.

21. Lorente M, Scherrer SS, Ammann P, Jobin M, Wiskott HW. Low temperature degradation of a Y-TZP dental ceramic. Acta Biomaterialia 2011;7(2):858-65.

22. Kosmač T, Kocjan A. Ageing of dental zirconia ceramics. Journal of the European Ceramic Society 2012;32:2613-22.

23. Sailer I, Zembic A, Jung RE, Siegenthaler D, Holderegger C, Hämmerle CHF. Randomized controlled clinical trial of customized zirconia and titanium implant abutments for canine and posterior single-tooth implant reconstructions: preliminary results at 1 year of function. Clinical Oral Implants Research 2009;20(3):219-25. 
24. Sailer I, Hammerle CHF. Zirconia ceramic single-retainer resin-bonded fixed dental prostheses (RBFDPs) After 4 years of clinical service: a retrospective clinical and volumetric study. The International Journal of Periodontics \& Restorative Dentistry 2014;34(3):333-43.

25. Garvie RC, Nicholson PS. Phase analysis in zirconia systems. Journal of the American Ceramic Society 1972;55(6):303-5.

26. Toraya H, Yoshimura M, Somiya S. Calibration curve for quantitative analysis of the monoclinic-tetragonal $\mathrm{ZrO}_{2}$ system. Journal of the American Ceramic Society 1984; 67:C199-221.

27. Chevalier J, Gremillardl. Deville S. Low-temperature degradation of zirconia and implications for biomedical implants. Annual Review of Materials Research 2007; $37: 1-32$.
28. Chevalier J, Calles B, Drouin JM. Low temperature aging of Y-TZP ceramics. Journal of the American Ceramic Society 1999;82(8):2150-4.

29. Deville S, Gremillard L, Chevalier J, Fantozzi G. A critical comparison of methods for the determination of the aging sensitivity in biomedical grade yttria-stabilized zirconia. Journal of Biomedical Materials Research Part B: Applied Biomaterials 2005;72(2):239-45.

30. Young RA. The rietveld method. Oxford: New York; 1995.

31. Deville S, Chevalier J, Gremillard L. Influence of surface finish and residual stresses on the ageing sensitivity of biomedical grade zirconia. Biomaterials 2006;27(10):2186-92.

32. Matsui $\mathrm{K}$, Ohmichi N, Ohgai M, Yoshida H, Ikuhara Y. Grain Boundary segregation-induced phase transformation in yttria-stabilized tetragonal zirconia polycrystal. Journal of the Ceramic Society of Japan 2006;114(1327):230-7. 